
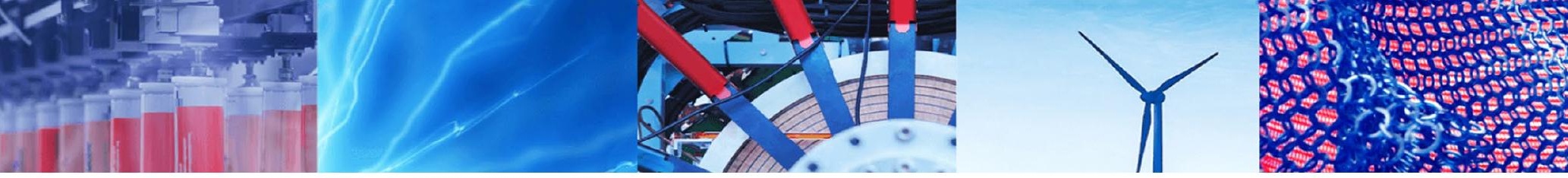

Research Article

\title{
A comparative study of RANS-based turbulence models for an upscale wind turbine blade
}

\author{
Patrick Irungu Muiruri ${ }^{1}\left[\right.$ D $\cdot$ Oboetswe Seraga Motsamai $^{1} \cdot$ Rehema Ndeda $^{1}$
}

(c) Springer Nature Switzerland AG 2019

\begin{abstract}
Computational fluid dynamic (CFD) numerical simulations are providing alternative to experimental methods in preliminary analysis of aerodynamic behavior for large wind turbines. Shortcomings inherent by experimental methods have popularized the three dimensional CFD methods. This paper, therefore, presents a numerical analysis for NREL 5MW wind turbine rotor using a single moving reference frame approach. ANSYS Fluent is employed to model airflow over the blade's surfaces using Reynolds average Navier-Stokes equations. A steady-state incompressible pressure based solver is applied in form of absolute velocity formulation. Four turbulence models are used: $k-\omega \mathrm{SST}, k-\epsilon \mathrm{RNG}, k-\epsilon$ realizable and Spalart Allmaras to determine the aerodynamic torque. Mesh independence study and validation is also performed. In addition, the predicted flap-wise bending load and comparison of pressure distribution for the four turbulence models are evaluated at different sections of the blade. Due to absence of experimental data for employed blade model, the obtained aerodynamic torque was compared with other reliable numerical simulation results.
\end{abstract}

Keywords Computational fluid dynamics · Aerodynamic torque · Turbulence models · Pressure coefficient

\section{Introduction}

The increased need to harness more green energy has driven the scaling up of offshore wind turbines. The amount of power generated by a turbine depends on the airfoil characteristics, blade twist distribution and rotor diameter. According to Fuglsang and Madsen [1], increasing the rotor diameter yields higher power compared to changing the shape of the blade. The larger rotor diameter, however, introduces complexity in the aerodynamics of the blades. This necessitates an accurate method to predict aerodynamic load and performance.

Traditional experimental methods are becoming obsolete due to the absence of working examples to use as prototypes or starting points for the design [2], owing to the fact that the largest blade in production currently is more than $61.5 \mathrm{~m}$ long [3]. These methods are also considered time-consuming and labour intensive. This has led to the popularity of semi-empirical and computational fluid dynamics (CFD) methods, which are less costly, and provide predictive data prior to blade construction. Semiempirical correlations such as BEM theory have been applied widely [4-6]. These methods utilize predetermined airfoil data as inputs and are typically used to model three dimensional (3D) effects of the flow. Despite these capabilities, semi-empirical correlations are limited to a specific set of assumptions and the definition of boundary conditions. The CFD method addresses these discrepancies inherent in experimental and semi-empirical based methods, since it is possible to define real-life operating conditions of the wind turbines $[2,7]$. It also provides insight into flow phenomena with regard to the aerodynamics of the rotor.

Reynolds-averaged Navier-Stokes (RANS), Large Eddy Simulation (LES) and Direct Numerical Simulation (DNS) are the most commonly used methods for CFD simulation

$\triangle$ Patrick Irungu Muiruri, pmuiruri@jkuat.ac.ke; Oboetswe Seraga Motsamai, MOTSAMAI@mopipi.ub.bw;

Rehema Ndeda, reheman@eng.jkuat.ac.ke | 'University of Botswana, Private bag UB 0061, Gaborone, Botswana.

SN Applied Sciences (2019) 1:237 | https://doi.org/10.1007/s42452-019-0254-5

Received: 20 November 2018 / Accepted: 12 February 2019 / Published online: 18 February 2019

SN Applied Sciences

a SPRINGer Nature journal 
of wind turbines [8]. These methods vary in accuracy and computation rates. The DNS method solves a wide range of scales and often requires a high number of nodes, which makes it the most computationally expensive method. Although closure models are unnecessary to solve Navier-Stokes equations using this method, simulating state-of-art engineering problems is not feasible, particularly for high Reynolds number flows $[8,9]$. The LES method is regarded as more accurate than RANS method, although it requires a substantially finer mesh than that applied to the RANS method. This high density grid requires powerful computational resources.

The RANS method, on the other hand is reasonably robust with satisfactory accuracy. However, this method experiences a closure problem due to unknown time-correlations of velocity known as Reynolds-stress that exist in the averaged equations [9]. The turbulent stresses are coupled with the RANS equations through eddy turbulent viscosity for RANS method based on Eddy Viscosity Models (EVM). The EVM models are broadly used in prediction of the performance of horizontal axis wind turbines (HAWTs) performance $[2,10,11]$, but are limited in their ability to predict flow field correctly. The Boussinesq hypothesis is employed in the RANS based models such as Spalart-Allmaras (S-A), $\mathrm{k}-\epsilon$ and $\mathrm{k}-\omega$. Using this approach, the computational time associated with calculation of eddy turbulent viscosity $\left(\mu_{t}\right)$ is relatively low, but, $\mu_{t}$ is assumed to be an isotropic scalar quantity, which rules out any turbulence anisotropy.

Different turbulence models have different predictive capabilities, depending on the properties of the blade as well as the boundary conditions of the model [12]. For this reason, the choice of turbulence models is likely to influence the accuracy of the CFD prediction. Commonly studied turbulence models include one-equation models (Spalart-Allmaras (SA) [13]) and two equations models (K- $\omega$ standard and SST [14], K- $\epsilon$ RNG and Realizable $[15,16])$. Villalpando et al. [17] assessed the best performing turbulence model for NACA63-415 airfoil by evaluating the coefficient of lift and coefficient of drag for different mesh sizes and angles of attack. The pressure coefficient distribution was also examined when the airfoil was rotated to the highest angle of attack. The Reynolds Stress method (RSM) was ruled out due to its sub-par predictions for the icing conditions of the model. A similar study conducted for the NACA 0015 airfoil by Kekina and Suvanjumrat [18] investigated the appropriate turbulence model by evaluating the lift coefficient and drag coefficient while varying the angle of attack. The least average error was observed in the Menter SST K- $\omega$ model. Kody et al. [19] examined the most suitable turbulence model using a 3D blade and compared the pressure coefficients at different positions of the blade. The Spallart-Allmaras model had better convergence and lower computing cost while the k- $\omega$ turbulence model showed better performance at higher wind speeds. It is important to note that these studies exhibited the reliance of predictive capabilities on boundary conditions of the study. There are, also, limited studies which focus on the ability of the turbulence models to predict the flap-wise bending moment and aerodynamic torque.

This study compared the performance of four best performing turbulence models. These models are: oneequation model known as Spalart-Allmaras (S-A); twoequations model k- $\epsilon$ RNG; $\mathrm{k}-\epsilon$ Realizable and Menter $\mathrm{k}-\omega$ SST. The aerodynamic torque of the NREL $5 \mathrm{MW}$ rotor blade [20] was evaluated using the single moving reference frame (SMRF) approach on ANSYS Fluent. The SMRF approach with sphere influence mesh around the blade surface was selected based on the availability of computational resources as well as its ability to adequately describe the complexity of the problem [21, 22]. Mesh sensitivity study was conducted to ensure accuracy and sufficient computational speed. In order to validate these models, the resulting aerodynamic torque was compared to the baseline aerodynamic torque generated using FAST code [23]. The performance of the blade was also evaluated by varying velocities from the rated wind speed to the cutout wind speed. The predictive capabilities of the different turbulence models on pressure coefficient distribution and the flapwise bending moment were also examined at inboard, middle and outboard sections of the blade.

\section{Methodology}

\subsection{Computational analysis}

A single moving reference frame (SMRF) approach was used to account for rotation of the wind turbine. This approach transforms the unsteady aerodynamic behavior of flow to steady state by treating blade as an inertial reference frame with respect to moving reference frame. In ANSYS Fluent, the moving frame uses either the relative velocity formulation or the absolute velocity formulation [12]. The absolute velocity formulation suits the current problem since the blade remains stationary unlike in relative velocity method where the rotor blades rotate at a constant rotational speed.

The relation of the absolute velocity, $U_{a}$ and the rotational velocity, $U_{r}$ observed from a moving coordinate system using right hand thumb rule is given by Eq. 1 [12].

$U_{r}=U_{a}-\Omega \times r$

Angular velocity of the rotating frame is denoted by $\Omega$.

The Navier-Stokes equation relates the velocity of inertial frame and rotating velocity of the reference frame 
to the acceleration of the flow which is augmented by an additional term incorporated in the conservation of momentum equation [12]. Relating Eq. 1 to the basic principles of conservation of mass and momentum, and considering incompressible flow yields Eq. 2 for momentum conservation and Eq. 3 for mass conservation.

$$
\begin{aligned}
& \left(U_{r} \cdot \nabla\right) U_{r}+\left[\Omega \times\left(U_{r}-\Omega \times r\right)\right] \\
& \quad=\frac{1}{\rho} \nabla \cdot p+\nabla\left(v+v_{t}\right) \nabla\left(U_{r}+\left(\nabla \cdot U_{r}\right)^{T}\right)
\end{aligned}
$$

$$
\nabla \cdot U_{r}=0
$$

Rotational effects such as coriolis force and centrifugal force are singled out by last term $\left[\Omega \times\left(U_{r}-\Omega \times r\right)\right]$ on the left hand side of Eq. (2). Kinematic and turbulent kinematic viscosity of the fluid are denoted by $v$ and $v_{t}$ respectively. $p$ is static pressure.

\subsection{Geometry and mesh setup design}

In the present study, only one of the three blades is modelled, since they are symmetrically fixed to the hub at $120^{\circ}$ apart. In order to account for the other two blades, periodic boundary conditions were applied on the fluid domain. All other parts of wind turbines are outside the scope of the present work. In this regard, the total length of the blade modelled is $60.13 \mathrm{~m}$ span, in addition to the $1.5 \mathrm{~m}$ hub allowance without considering the tip finishing part. The total radius of the rotor taken into consideration for simulation is, therefore, $61.63 \mathrm{~m}$. The geometric coordinates of different airfoils, chord and twist angle presented by [20] and were used in this study. The aerodynamic centre coincides with the pitch axis which lies at $25 \%$ of the blade chord measured from leading edge for the blade part made of airfoil, whereas in the cylinder part the aerodynamic centre lies at the centre of the diameter. The 3D blade model was reproduced using ANSYS workbench. Figure 1 shows the CAD model employed in the present study.

The fluid domain including the position of the blade in the domain and naming of the boundaries is illustrated in Fig. 2 The fluid domain is conical in shape. The inlet boundary was defined at $90 \mathrm{~m}$ upstream with a radius of $120 \mathrm{~m}$, whereas the radius of outlet boundary was specified to $270 \mathrm{~m}$ at $300 \mathrm{~m}$ downstream of the location of the blade.

The fluid domain was discretized into small hybrid computational cells comprising of structured prismatic wedge mesh around the blade surface and unstructured tetrahedral mesh. In attempt to arrest the boundary layers on the blade surface, fifteen inflation layers with transition rate of 0.2 and growth rate of 1.1 were inserted around the blade surface. The mesh strategy employed necessitated a dimensionless value of wall $y^{+}$ranging between 30 and 300 for the fully turbulent region [24]. The nondimensional wall $y^{+}$value was calculated by Eq. $4[12,24]$

$y^{+}=\frac{u_{\tau} y}{v}$

where $u_{\tau}$ denotes the friction velocity, $\mathrm{y}$ is the distance from the wall, $v$ is kinematic viscosity and $y^{+}$represents dimensionless distance measured from the blade surface (wall) to the viscous layer.

The sphere influence of $50 \mathrm{~m}$ radius was also defined from the centre point of the blade in the area bounding the blade with mesh size of $1 \mathrm{~m}$. The mesh size of the remaining domain was $3 \mathrm{~m}$. The proximity and curvature sizing functions were specified at global level as medium size on ANSYS Fluent. The maximum face and tetrahedron sizes were $6 \mathrm{~m}$ and $12 \mathrm{~m}$ respectively.

Mesh generation was implemented using bottom to top strategy such that, first, the edges were meshed
Fig. 1 CAD design of an offshore NREL 5MW baseline wind turbine blade

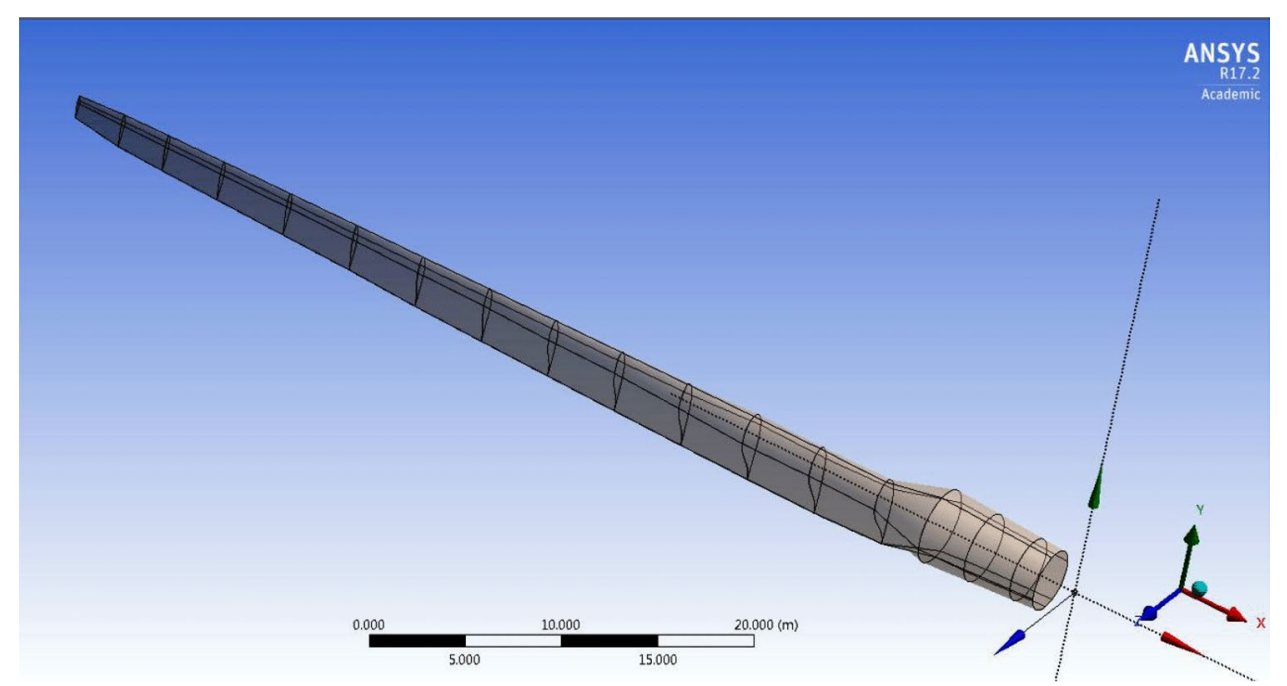

SN Applied Sciences A SPRINGer Nature journal 
Fig. 2 CFD simulation domain

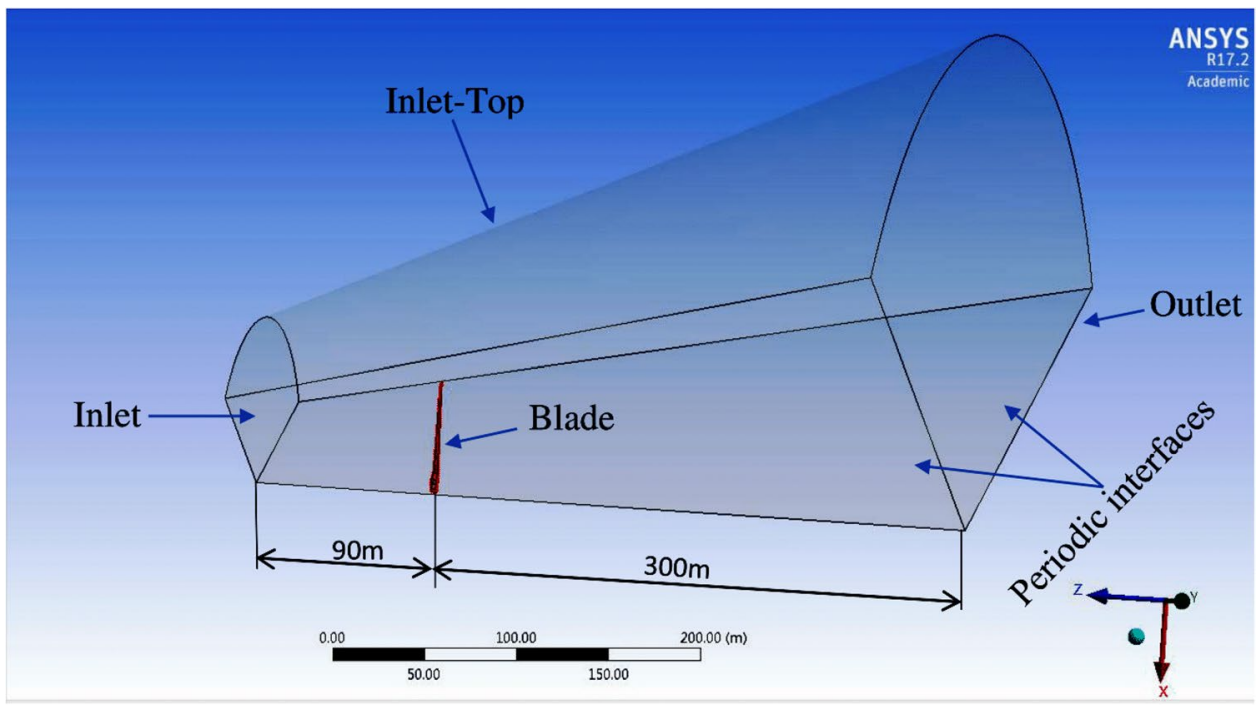

followed by faces and lastly, volumes. For each mesh generation, the quality of mesh elements was examined on the basis of skewness and orthogonal quality.

Prior to the study, a mesh sensitivity test was conducted by considering four different mesh sizes on the blade surface: $0.15 \mathrm{~m}, 0.10 \mathrm{~m}, 0.05 \mathrm{~m}$ and $0.03 \mathrm{~m}$. The generated mesh is shown in Fig. $3 \mathrm{~b}$ of cross-sectioned fluid domain.

\subsection{Boundary conditions}

Dirichlet boundary conditions were defined at the inlet and inlet-top with respective uniform inflow velocity dependent on simulations flow conditions. The flow was imposed in the $(0,0,-1)$ direction as illustrated in Fig 2. For purposes of validation and the mesh independence study, the inflow velocity was specified as $9 \mathrm{~ms}^{-1}$ at the inlet and inlet-top boundaries. At the outlet, the zero gauge pressure was specified in all simulations. The turbulent viscosity ratio and intensity were retained as $10 \%$ and $5 \%$ respectively. The blade surface was defined as a wall with no-slip boundary condition. Periodic boundary conditions were imposed on two sides of the fluid domain to account for the other two blades. For the validation study, the reference frame was set to rotate at an angular velocity, $\Omega$ of $10.3 \mathrm{rpm}$. Subsequent simulations were performed at $12.1 \mathrm{rpm}$ with flow velocity greater than $10 \mathrm{~ms}^{-1}$. In the current study, the wind turbine was considered to operate below 0.3 Mach number (Ma) [25]. Based on this, the fluid (air) density was considered constant at sea level $\left(\rho=1.225 \mathrm{kgm}^{-3}\right)$ and fluid viscosity of $1.82 \times 10^{-5} \mathrm{~kg} / \mathrm{ms}^{-1}$.

\subsection{Numerical solution}

The finite volume method was used on ANSYS FLUENT. Three dimensional double precision and parallel scheme was employed in all simulations. A small cluster was developed by connecting four HP Desktop computers, where each computer node contributed four cores which were auto-connected using Intel MPI (pcmpi) option. Each computer was installed with $\mathrm{x}-64$ bit Operating System (OS) window and Intel(R) Core (TM) i7-4790 CPU @ 3.40GHz processor. The master computer had a memory of $16 \mathrm{~GB}$ RAM while each of the other three computers had $8 G B$ RAM. The mesh was partitioned into sixteen equal portions automatically by METIS algorithm.

A steady pressure based solver associated with absolute velocity formulation was employed to model flow fields. A Semi-Implicit Method for Pressure-Linked Equations (SIMPLE) algorithm [12] was used to decouple velocity and pressure in a segregated manner. In this approach, the pressure variable was first computed using the pressure correction equation which manipulates the continuity and momentum equations implicitly. Afterwards, velocity variables were obtained from the momentum equations explicitly.

The RNG $k-\epsilon$ turbulence model is considered less computationally expensive compared to the $k-\epsilon$ Realizable and $k-\omega$ SST models [26]. It was, therefore, used together with the RANS equations for the mesh sensitivity study. Wall enhancement functions were enabled for $k-\epsilon$ RNG and $k-\epsilon$ Realizable in an attempt to resolve the fully turbulent layer all the way to the blade surface [27]. $k-\omega$ SST which consists of hybrid of $k-\omega$ and $k-\epsilon$ formulations was also considered owing to the fact that it performs well 
Fig. 3 Resultant mesh
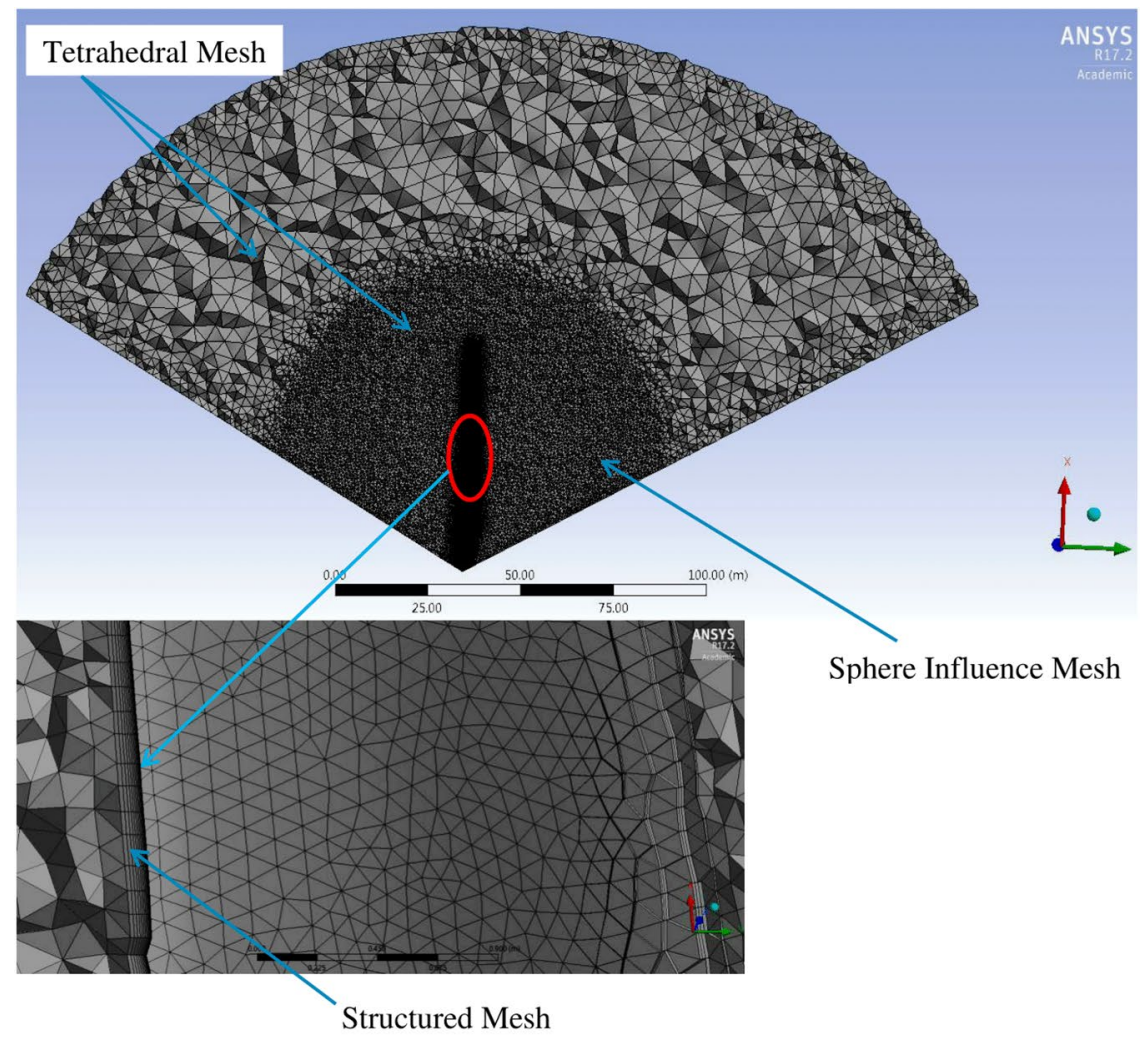

Sphere Influence Mesh

(a) Mesh along the blade's span

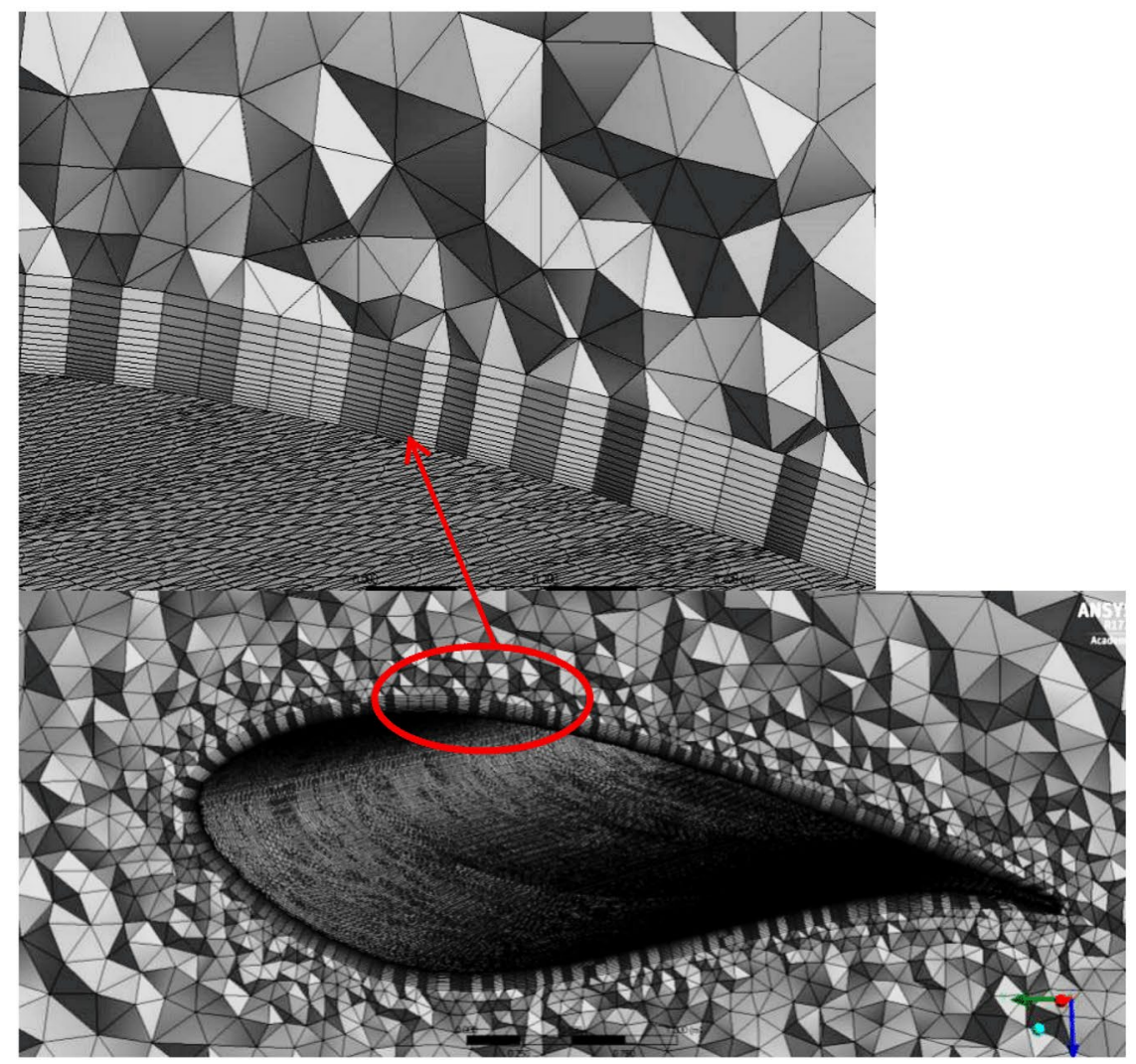

(b) Mesh across the blade's chord 
Table 1 Mesh independence study

\begin{tabular}{lccllcc}
\hline $\begin{array}{l}\text { Blade mesh } \\
\text { size }(\mathrm{m})\end{array}$ & Nodes $\left(\times 10^{6}\right)$ & Total Mesh $\left(\times 10^{6}\right)$ & $\begin{array}{l}\text { Average } \\
\text { skewness }\end{array}$ & $\begin{array}{l}\text { Average } \\
\text { orthogonal }\end{array}$ & $\begin{array}{l}\text { Time }(\mathrm{h}) \\
\text { oerodynamic }\end{array}$ & $\begin{array}{l}\text { Aedrae }(\mathrm{kNm}) \\
\text { Torque }\end{array}$ \\
\hline 0.15 & 1.424 & 6.785 & 0.224 & 0.856 & 5 & 1857 \\
0.10 & 1.980 & 8.273 & 0.223 & 0.868 & 14 & 2631 \\
0.05 & 4.920 & 15.984 & 0.213 & 0.886 & 21 & 2740 \\
0.03 & 11.829 & 33.812 & 0.202 & 0.902 & 51 & 2737 \\
\hline
\end{tabular}

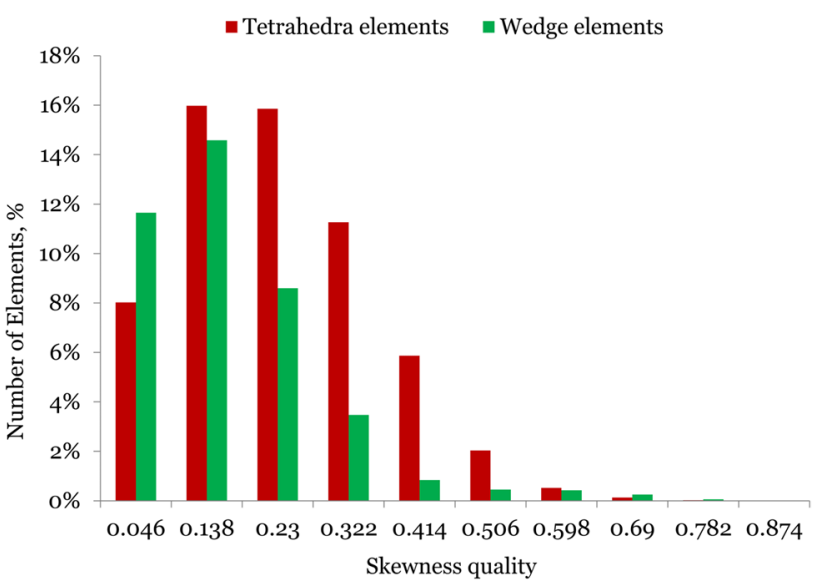

Fig. 5 Mesh elements skewness quality

The speed of numerical computation largely depends on the virtual memory and power of the processor. More mesh elements implies that more virtual memory will be required to solve all mathematical equations in the grid. On the other hand, the quality of mesh also influences the computational speed as well as accuracy of the obtained resolution. For this reason, the blade surface mesh size of $0.05 \mathrm{~m}$ (estimated elements $=15.812$ millions cells) was found to have satisfactory computational speed and accuracy. The quality of generated elements was found to be within the range of $0-0.93$ in term of skewness quality and between $0.06-1.0$ in terms of orthogonal quality as shown in Figs. 5 and 6.

The green bars represent prismatic mesh formed by inserting inflation layers around the blade surface while the red bars indicate tetrahedrons elements in the domain.

To check whether the boundary layer effects were correctly resolved, Fig. 7 typically presents distribution of contour of wall $y+$ on the blade surface at $15 \mathrm{~m} / \mathrm{s}$ for solution solved using $k-\omega \mathrm{SST}$ turbulence model. The value of wall $y^{+}$increases near the leading edge approaching the blade tip section. This region if probably experience more viscous shear friction. In order to reduce the value of wall $y^{+}$more refine meshes are need in which it decreases computational efficiency. Since the value of $y^{+}$was found to be within the recommended range, a compromise was decided between the accuracy and computational selected. 


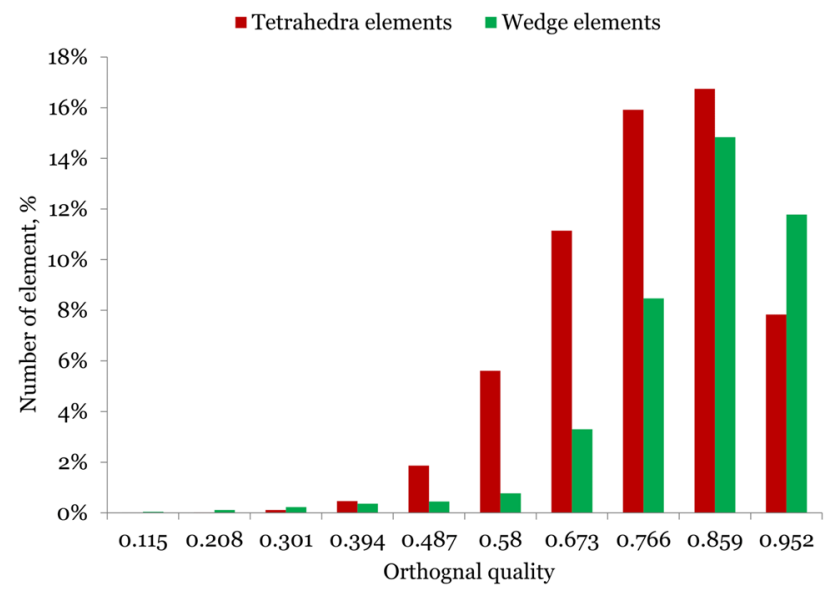

Fig. 6 Mesh elements orthogonal quality

efficiency. Even though the attained value of $y^{+}$was found within the required range for fully turbulent region in ANSYS FLUENT [12], from observation, an alternative way to arrest boundary layer appropriately could have been achieved by defining the first inflation layer distance.

\subsection{Validation of the model}

All calculations were performed for 9000 iterations and the solutions were deemed converged when most of the residuals dropped to at least $10^{-5}$ order. In addition, mass imbalance and thrust force in Z-axis $(0,0-1)$ direction were monitored. The resolution of fluid flow in the domain was verified by checking the mass-flux imbalance between inlet, inlet-top and outlet openings. In the present study, the imbalance mass-flux dropped below $0.1 \%$, which was a good indication that the flow resolved well. The thrust force was monitored until minimal change was observed from Residual tolerance values of all monitored variables dropped to less than $10^{-5}$, except for turbulent kinetic energy $(k)$. This is a good indication that the convergence criterion was met.

The accuracy of the model was further checked by comparing the obtained aerodynamic torque with works of other researchers [21,29-31]. Table 2 compares the aerodynamic torque results to similar studies in literature.

The obtained results from the $k-\omega \mathrm{SST}, k-\epsilon \mathrm{RNG}$ and $k-\epsilon$ Realizable compare closely to similar numerical studies. The higher differences observed in comparison with work of Jonkman et al. [20] could be attributed to the use of empirical data in the FAST code contrary to CFD computation, which employs real-life operating conditions. $k-\omega$ SST compared well with the studies $[21,29]$ and [30]. Despite using similar computation approach of single moving reference frame, there is a slightly higher difference of about $5 \%$ between $k-\omega$ SST and the study

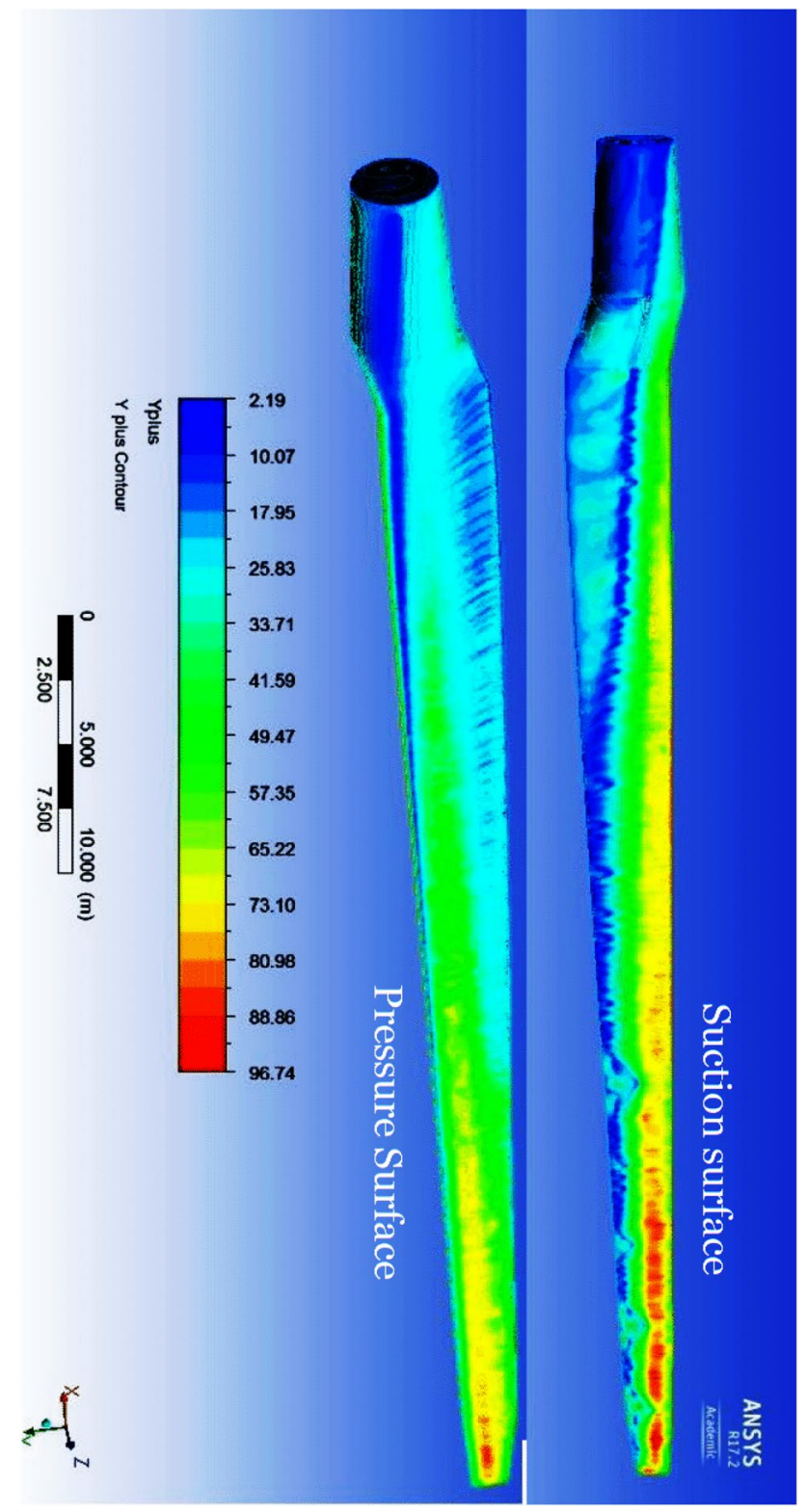

Fig. 7 Typical distribution of dimensionless value of wall $y^{+}$

Table 2 Comparison of aerodynamic torque

\begin{tabular}{lll}
\hline Model & Solver & Torque $(\mathrm{kNm})$ \\
\hline Jonkman et al. [20] & FAST & 2500 \\
Bazilevs et al. [29] & NURBS & 2670 \\
Siddiqui et al. [21] & OpenFoam & 2650 \\
Siddiqui et al. [31] & OpenFoam & 2800 \\
Siddiqui et al. [30] & OpenFoam & 2682 \\
$k-\omega$ SST & & 2664 \\
$k-\epsilon$ RNG & & 2740 \\
$k-\epsilon$ Realizable & & 2768 \\
\hline
\end{tabular}


by Siddiqui et al. [31]. It can be concluded that refinement of the mesh near the blade surface improve the accuracy closer to $[21,29]$

\subsection{Prediction of aerodynamic torque}

The predictive capabilities of four turbulence models $k-\omega$ $\mathrm{SST}, k-\epsilon$ RNG and $k-\epsilon$ and Spalart Allmaras were investigated. The aerodynamic torque and flap-wise bending load were examined for various wind speed; $9 \mathrm{~ms}^{-1}, 15$ $\mathrm{ms}^{-1}, 20 \mathrm{~ms}^{-1}$ and $25 \mathrm{~ms}^{-1}$. The pitch angle of the blade was held constant as $0^{\circ}$. The present results were compared with work of Zhao et al. [30]. Figure 8 plots the curves of aerodynamic torque against flow velocities.

At velocity of $9 \mathrm{~ms}^{-1}$, the turbulence models exhibited similar predictive capability. However, the difference in predictions increased with increase in velocity. Absence of experimental data made it difficult to evaluate the best model based on aerodynamic torque at high velocities. The work of Zhao et al. [30], was, therefore, adopted for comparison with the present study at different wind speeds: $9 \mathrm{~m} / \mathrm{s}, 15 \mathrm{~m} / \mathrm{s}, 20 \mathrm{~m} / \mathrm{s}$ and $25 \mathrm{~m} / \mathrm{s}$, while the blade pitch angle was held constant at zero degrees.

The plotted curve of $k-\omega$ SST deemed closer to the curved obtained from [30] as compared with others. Exact matching of the results was not anticipated given that not all fluid properties utilized in their work are revealed. The turbulence model used in Zhao et al's work is also not clear, since it is not highlighted in their journal article. In that regard, Zhao et al.'s [30] work was used as a general baseline to compare the aerodynamic torque of the four investigated turbulence models. The $\mathrm{k}-\epsilon$ Realizable model over-predicted aerodynamic torque. It can be concluded that $k-\omega \mathrm{SST}$ and $k-\epsilon \mathrm{RNG}$ are the suitable turbulence models that may be utilized to predict aerodynamic

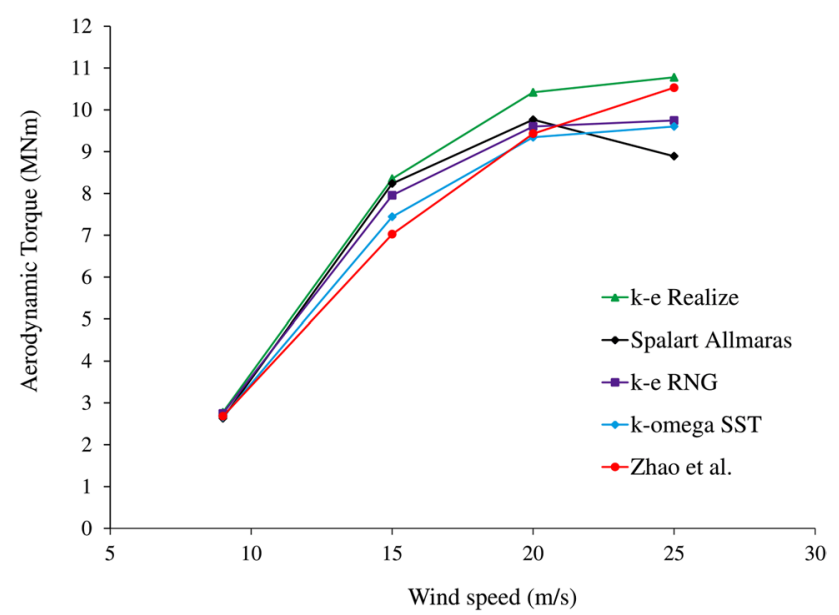

Fig. 8 Plots of aerodynamic torque against wind speed of different turbulence models torque at high wind speed. They show consistency and the minimal difference when compared with results from Zhao et al [30]. However, a different opinion is demonstrated on observation of the flap-wise bending moment caused by aerodynamic load (pressure on the blade surface).

\subsection{Prediction of flap-wise bending moment}

Figure 9 compares the flap-wise bending load of the four turbulence models. At $9 \mathrm{~ms}^{-1}$, the Spalart Allmaras model predicted the lowest flap-wise bending moment while the other three models gave almost similar predictions.

Flap-wise bending moment increases with increase in wind speed to $15 \mathrm{~m} / \mathrm{s}$. Between $15 \mathrm{~m} / \mathrm{s}$ and $25 \mathrm{~m} / \mathrm{s}$, a similar trend is observed for Spalart Allmaras and $k-\omega$ SST models. Unlike in prediction of aerodynamic torque, the flap-wise bending moment decreases with increase in wind speed from $15 \mathrm{~m} / \mathrm{s}$ and $25 \mathrm{~m} / \mathrm{s}$. In the work of Sagol et al [32], $k-\omega$ SST was found to fairly good compare the root flap-wise bending load with UAE data [33]. In the evaluation of the most suitable turbulence model in prediction of lift and drag forces below stalling angle of attack in the work of Kekina and Suvanjumrat [18], $k-\omega$ SST was found to compared reasonably with experimental measurements. Based on these facts, though in present study lack experimental data, $k-\omega$ SST can be concluded to give the best prediction of aerodynamic torque and flapwise bending load in relation to other turbulence models.

\subsection{Pressure distribution}

Aerodynamic torque and flap-wise bending moment are product of pressure distribution on the blade surface. A comparative study of pressure coefficient $\left(c_{p}\right)$ distribution

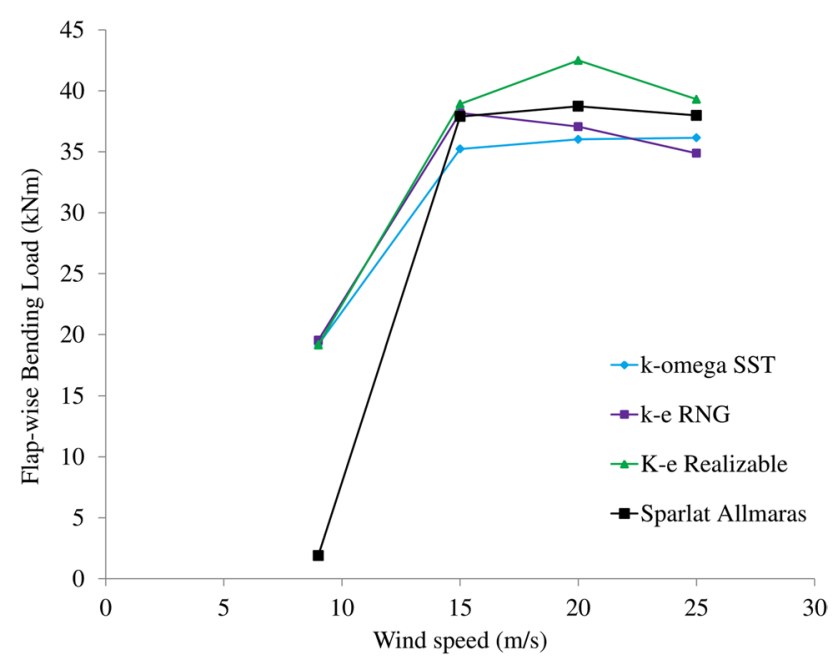

Fig. 9 Plots of flap-wise bending moment against wind speed of different turbulence models 
was carried out at three positions along the blade span at near hub 32\% R, mid-span 60\% R and near tip 92\% R. The comparison was done for different turbulence models at $15 \mathrm{~m} / \mathrm{s}$ and $20 \mathrm{~m} / \mathrm{s}$ respectively. The pressure coefficient was calculated by Eq. (5) [19, 32].

$c_{p}=\frac{P-P_{\infty}}{0.5 \rho_{\infty}\left(U_{\infty}^{2}+(\mathrm{r} \Omega)^{2}\right)}$

where $U_{\infty}$ is the free stream velocity, $r \Omega$ is the local rotational speed of the blade at corresponding radius ( $r$ ) of the blade span-wise, $\rho_{\infty}$ is a free stream density of the fluid flow, $P$ represent static pressure on the blade surface and $P_{\infty}$ denotes free stream atmospheric pressure.

Figure 10a and $\mathrm{b}$ illustrate comparison of the pressure coefficient at $32 \%$ R chord at $15 \mathrm{~m} / \mathrm{s}$ and $20 \mathrm{~m} / \mathrm{s}$ respectively. Figs. $11 \mathrm{a}$ and $\mathrm{b}$ compare pressure coefficient at mid span $60 \%$ R chord and lastly, Figs. 12a and b compare pressure coefficient at mid span $92 \% \mathrm{R}$ chord of the investigated baseline blade.

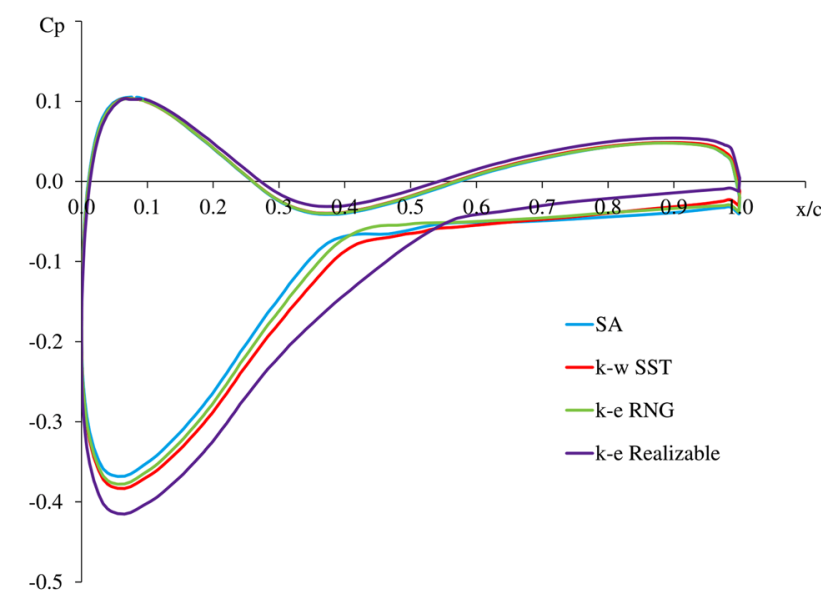

(a) $15 \mathrm{~m} / \mathrm{s}$

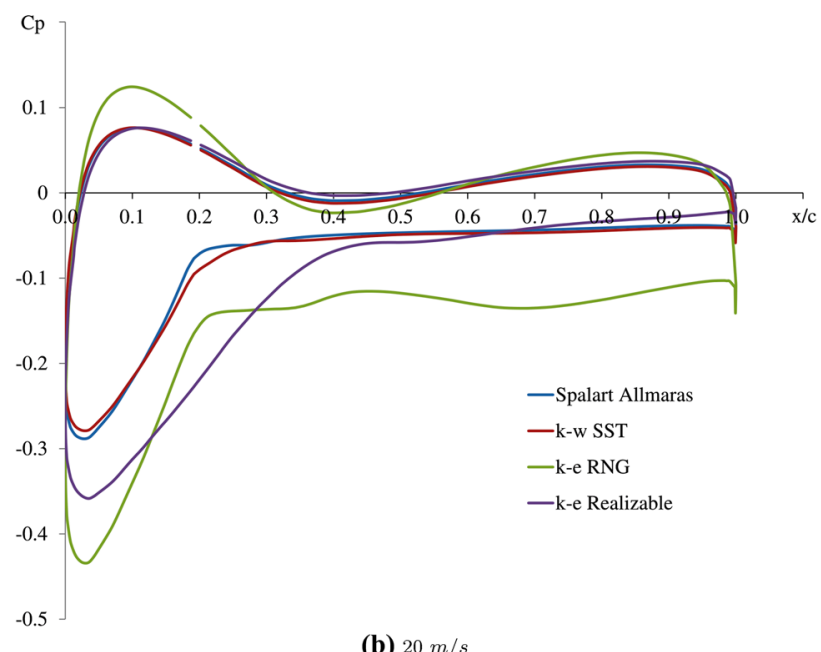

(b) $20 \mathrm{~m} / \mathrm{s}$

Fig. 10 Comparison of pressure coefficient for $32 \% \mathrm{R}$ chord

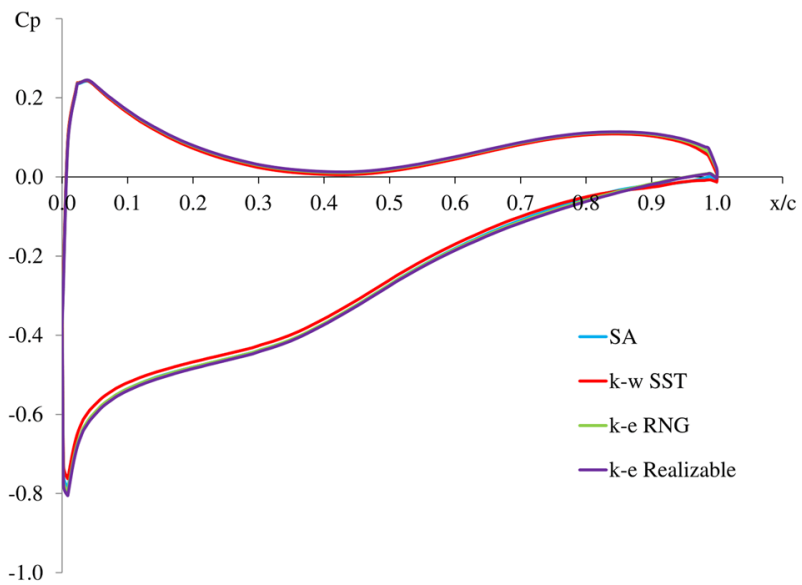

(a) $15 \mathrm{~m} / \mathrm{s}$

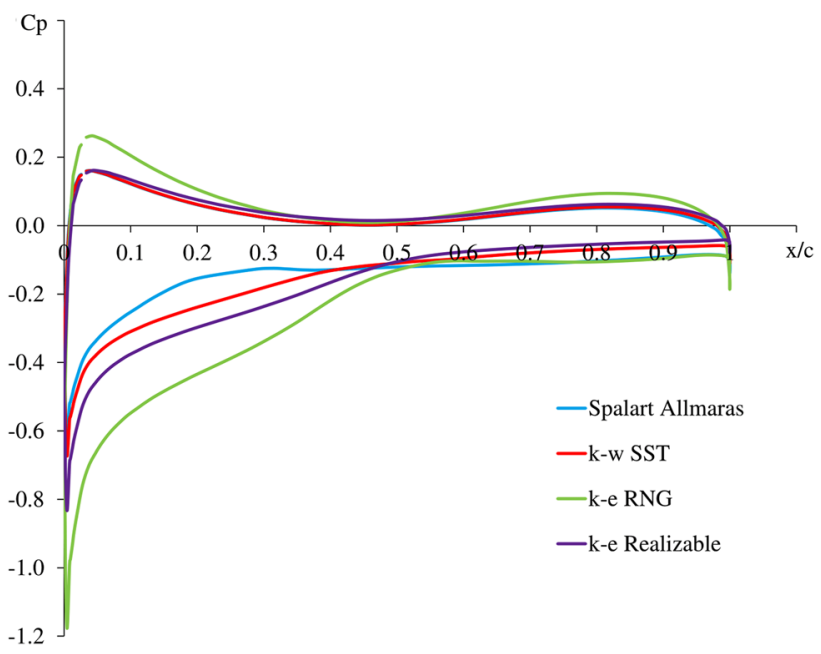

(b) $20 \mathrm{~m} / \mathrm{s}$

Fig. 11 Comparison of pressure coefficient for $60 \% \mathrm{R}$ chord

All turbulence models were observed to have close predictive capabilities on the pressure surface at $15 \mathrm{~m} / \mathrm{s}$ but predictions slightly vary for $k-\epsilon$ Realizable model and underestimation occurred for $k-\omega$ SST at $92 \%$ chord. Disperse predictions were revealed for both wind speeds 15 $\mathrm{m} / \mathrm{s}$ and $20 \mathrm{~m} / \mathrm{s}$ on the suction surface. For $15 \mathrm{~m} / \mathrm{s}$, the disperse prediction was observed near the root at $32 \%$ chord between the leading edge and mid-chord $(x / c=0.55)$, where $x / c$ is dimensionless chord and $x$ is the local chordwise coordinate. However, over-estimate was depicted by $k-\epsilon$ Realizable model at $15 \mathrm{~m} / \mathrm{s}$ and $k-\epsilon$ at $20 \mathrm{~m} / \mathrm{s}$. Authors in $[32,34]$ also made similar observations of lower accuracy at the suction surface than at the pressure surface. The accuracy is influenced by separation of flow that occurs on suction surface causing the turbulent air.

At $32 \% \mathrm{R}$ chord, Spallart Allmaras and $k-\omega$ SST are close in comparison but deviates at $60 \% \mathrm{R}$ chord and $92 \% \mathrm{R}$ chord for wind speed of $20 \mathrm{~m} / \mathrm{s}$. $k-\epsilon$ RNG was found to overestimate the pressure coefficient at $20 \mathrm{~m} / \mathrm{s}$ 


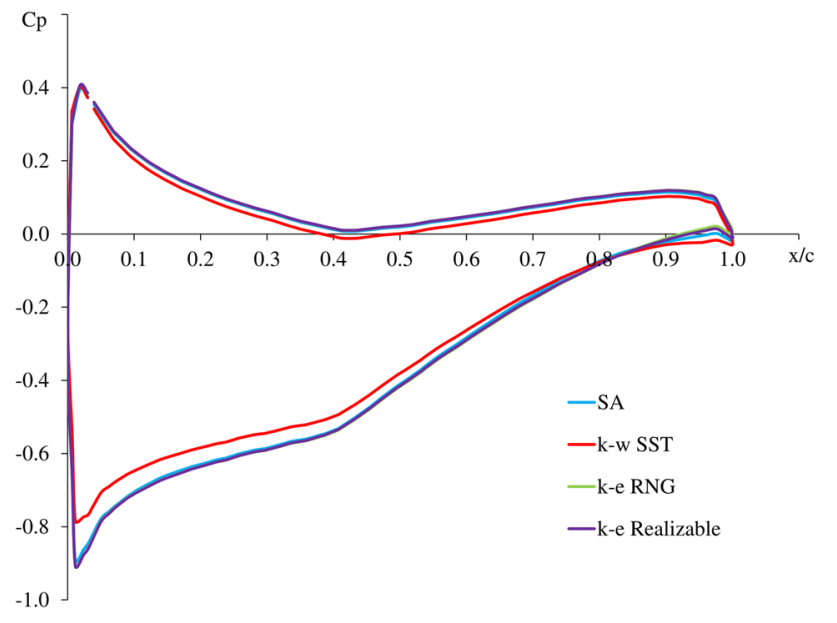

(a) $15 \mathrm{~m} / \mathrm{s}$

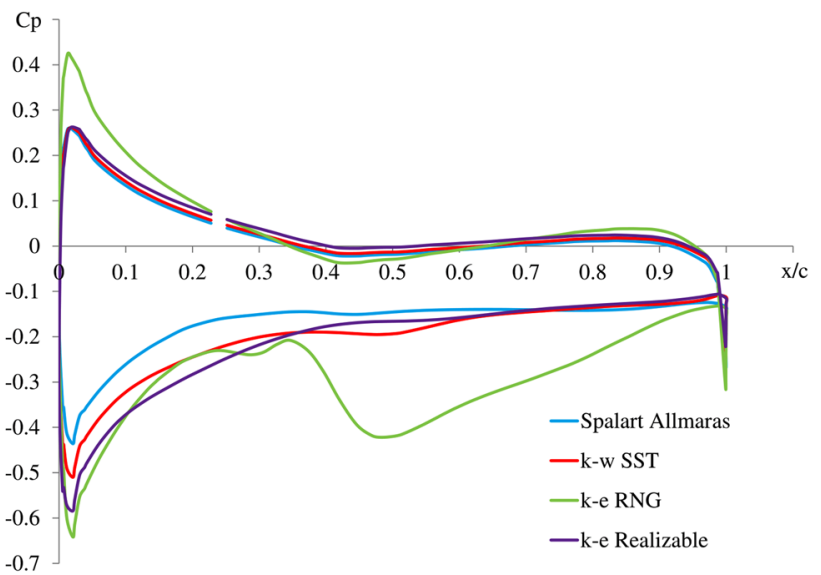

(b) $20 \mathrm{~m} / \mathrm{s}$

Fig. 12 Comparison of pressure coefficient for $92 \%$ R chord

throughout the blade's span. The margins between calculations of the pressure coefficient performed with Spallarat Allmaras, $k-\epsilon$ RNG and $k-\epsilon$ Realizable models are quite small at $60 \%$ R chord and $92 \%$ R chord for $15 \mathrm{~m} / \mathrm{s}$. At the same position, there is a large variance in the computations from one model to the other at $20 \mathrm{~m} / \mathrm{s}$ wind speed.

To get better insight on behaviour of physics that causes pressure load on the blade surface, pressure contours and velocity streamline plots are visualized for $k-\omega$ SST at $15 \mathrm{~m} / \mathrm{s}$ and $20 \mathrm{~m} / \mathrm{s}$ at respective span-wise positions. Figures 13, 14 and 15 illustrate the pressure spread and corresponding relative velocity probed at span-wise locations $32 \% \mathrm{R}, 60 \% \mathrm{R}$ and $92 \% \mathrm{R}$ respectively.

The flow separation is more pronounced near the root region as depicted in Fig. 13. The large flow separation occurs due to adverse pressure gradient resulting in high pressure near trailing edge. As a result, the separation of flow occurs causing the turbulent air formed behind the wake to decrease the pressure load on the pressure surface, causing an increase in pressure drag. Near the root region of the blade, flow with low velocity is experienced, and this can be attributed to flow separation as well. The blade profile at this region is highly twisted leading to high angle of attack that causes the flow to detach from the blade surface. Similar flow phenomena is also observed at $60 \% \mathrm{R}$ and $92 \% \mathrm{R}$ sections, but with little flow separation.

\subsection{Discussion}

There is hardly any experimental data for offshore NREL $5 \mathrm{MW}$ baseline wind turbine available in the literature on distribution of pressure coefficient on various chord spanwise, to the best of our knowledge. Lack of this information from reliable sources, make it difficult to settle on the best turbulence model for the most accurate approximation. For this reason, this analysis was conducted to determine the suitable turbulence model. Based on conclusions drawn from validation, comparison of aerodynamic torque and flap-wise bending moment, the k- $\omega$ SST model was found to be the most consistent, despite minimal variation of pressure coefficient at $20 \mathrm{~m} / \mathrm{s}$.

This is in agreement with literature sources which indicate that $k-\omega$ SST model is the most suitable turbulence models for CFD analysis of wind turbine $[17,32,35] . k-\omega$ SST model also showed improved separation prediction capabilities [36]. This feature is enhanced by $k-\omega$ SST blend function between $k-\omega$ and $k-\epsilon$ models, since the SST model is able to solve turbulence at the blade surface (wall) through $k-\omega$ and in the bulk flow upstream through $k-\epsilon$. Moreover, the use of a stress limiter under $k-\omega$ SST model improves calculations of eddy-viscosity, particularly at low Reynolds number flow.

\section{Conclusions and recommendation}

A single moving reference frame with sphere influence mesh near the blade surface has been employed for numerical computations of NREL $5 \mathrm{MW}$ wind turbine via ANSYS Fluent. The blade surface mesh of size $0.05 \mathrm{~m}$ with fifteen inflation layers around it, was found to give satisfactory accuracy and speed. The aerodynamic torque obtained from $k-\omega$ SST in comparison to other tested turbulence models showed remarkable agreement with adopted works.

The predictive capabilities of different turbulence models was also tested in prediction of aerodynamic torque and flap-wise bending load at various wind speeds. The resultant aerodynamic torque computed using different turbulence models at different operational wind speed (9 $\mathrm{m} / \mathrm{s}, 15 \mathrm{~m} / \mathrm{s}, 20 \mathrm{~m} / \mathrm{s}$ and $25 \mathrm{~m} / \mathrm{s}$ ) was compared to numerical results obtained from literature [30]. $k-\omega$ SST model showed closer agreement and consistent trend with 


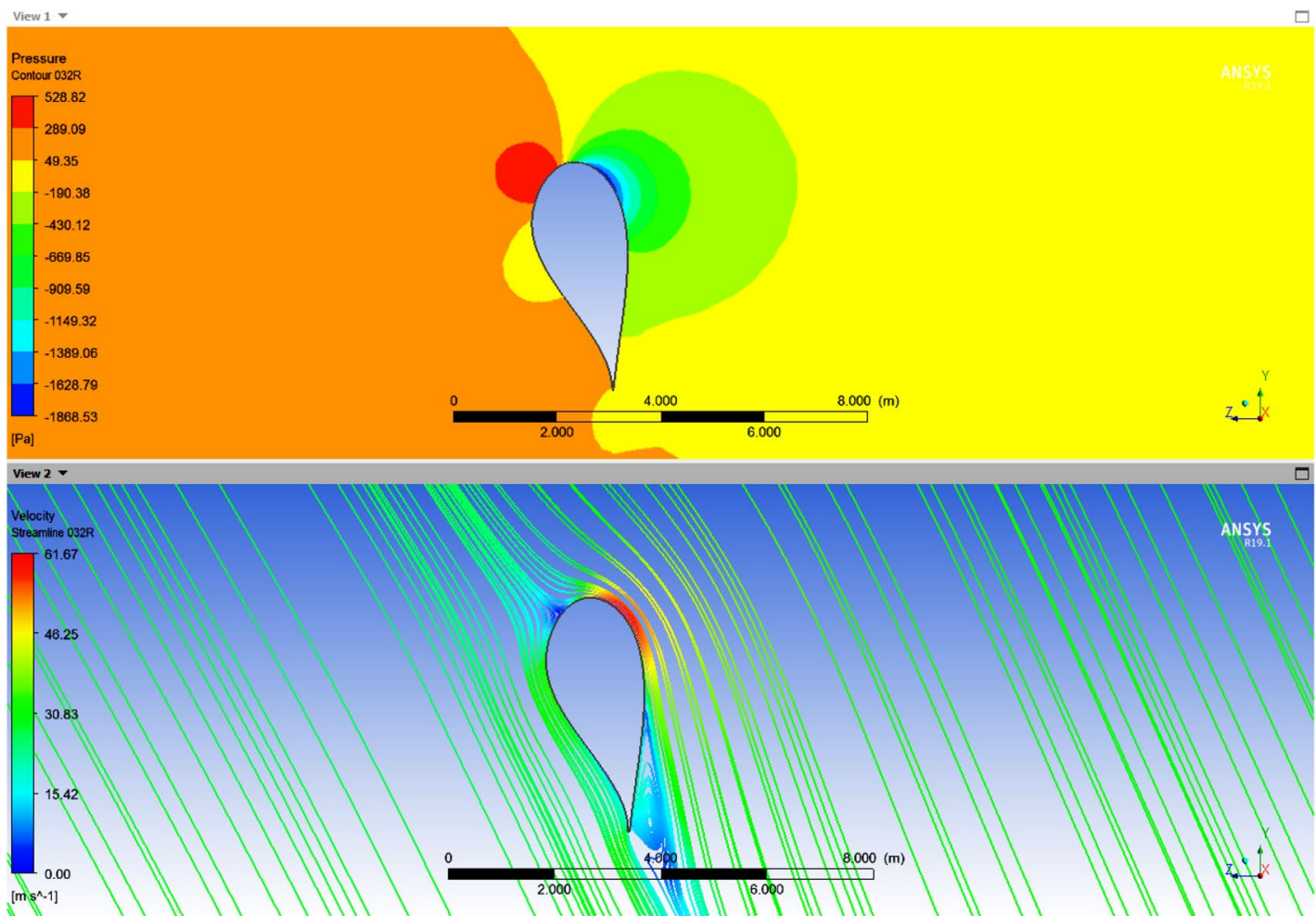

(a) $15 \mathrm{~m} / \mathrm{s}$

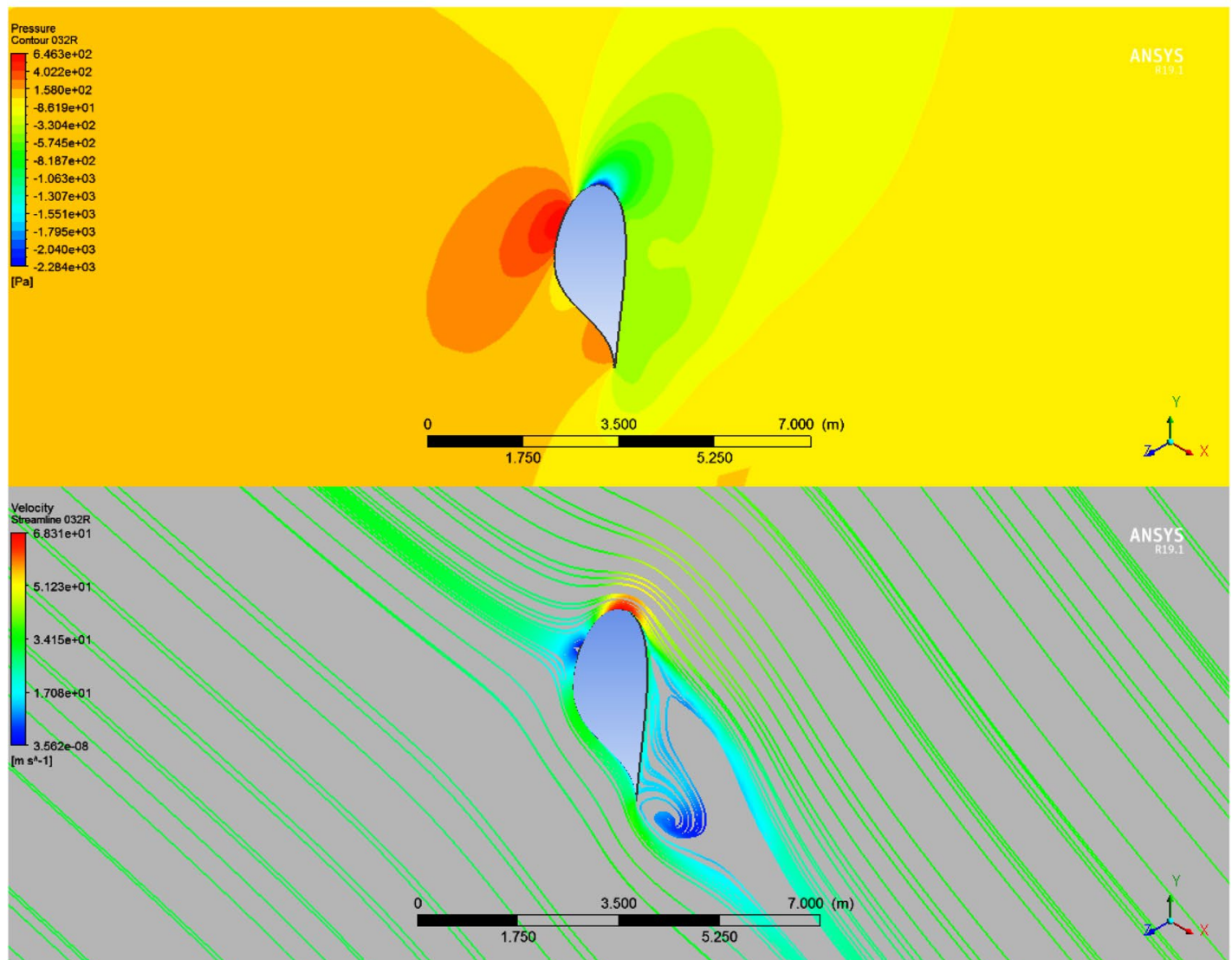

(b) $20 \mathrm{~m} / \mathrm{s}$

Fig. 13 Relationship between pressure contour and velocity streamlines in 32\% R span 


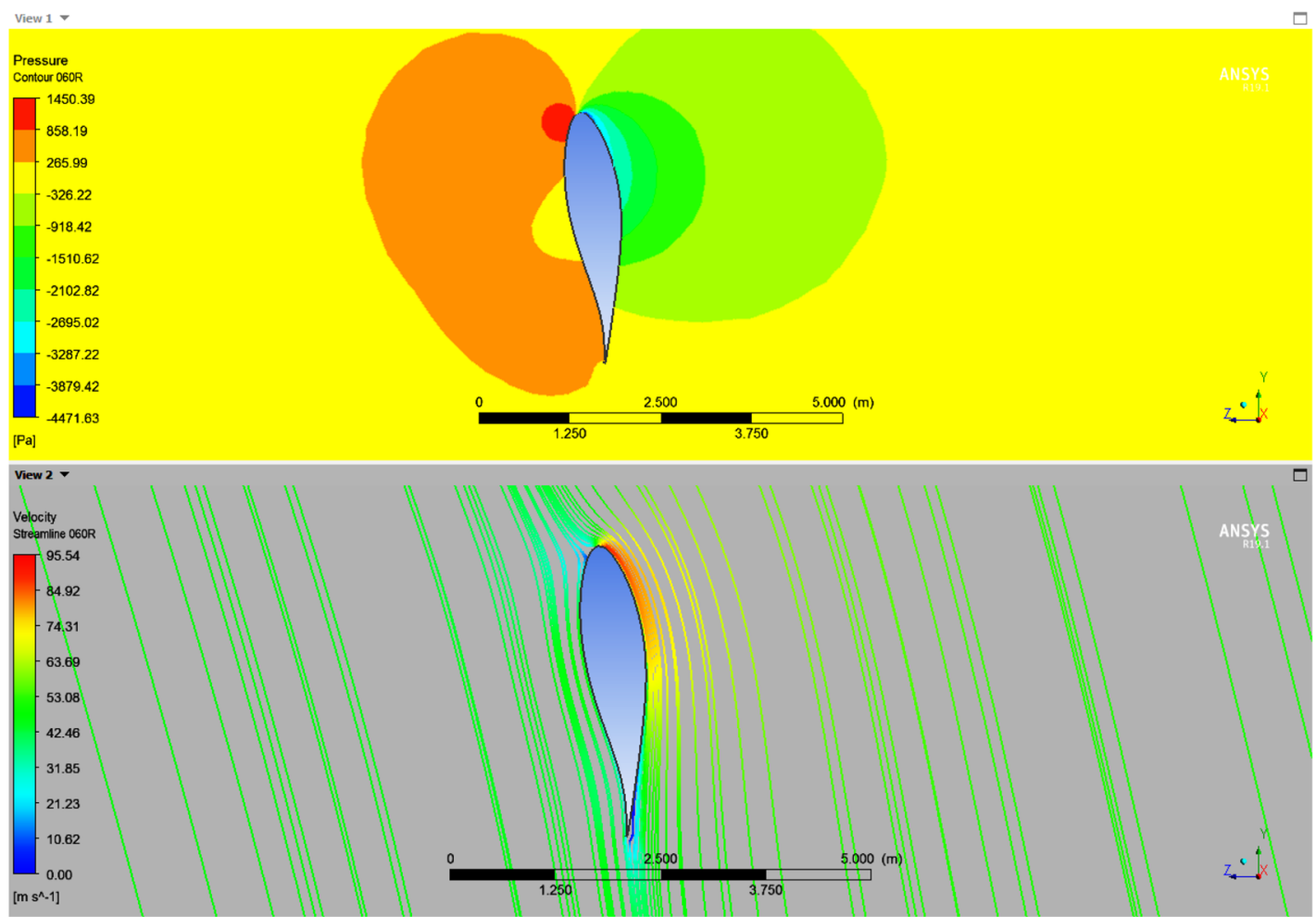

(a) $15 \mathrm{~m} / \mathrm{s}$

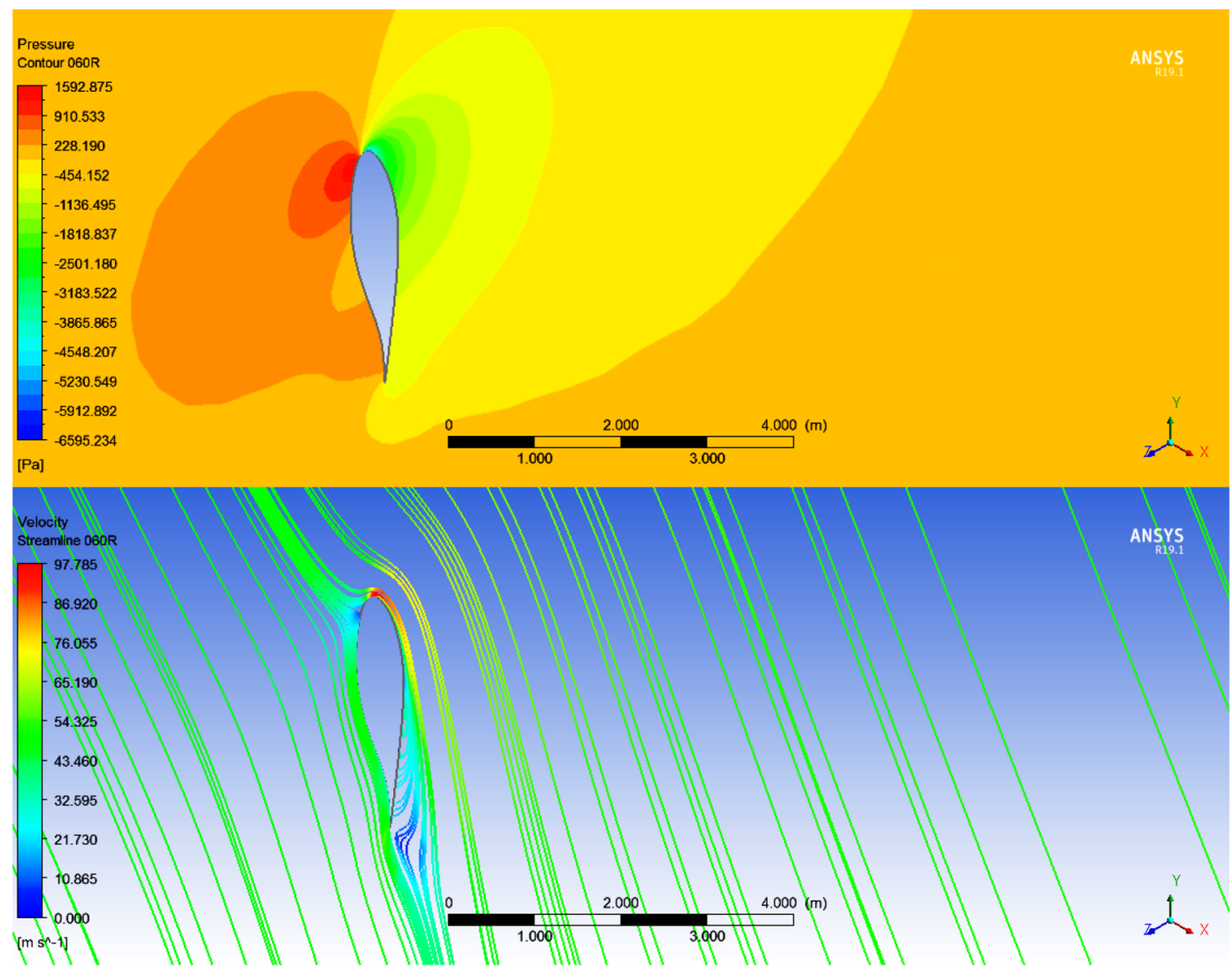

(b) $20 \mathrm{~m} / \mathrm{s}$

Fig. 14 Relationship between pressure contour and velocity streamlines in $60 \% \mathrm{R}$ span

\section{SN Applied Sciences}

a SPRINGER NATURE journal 


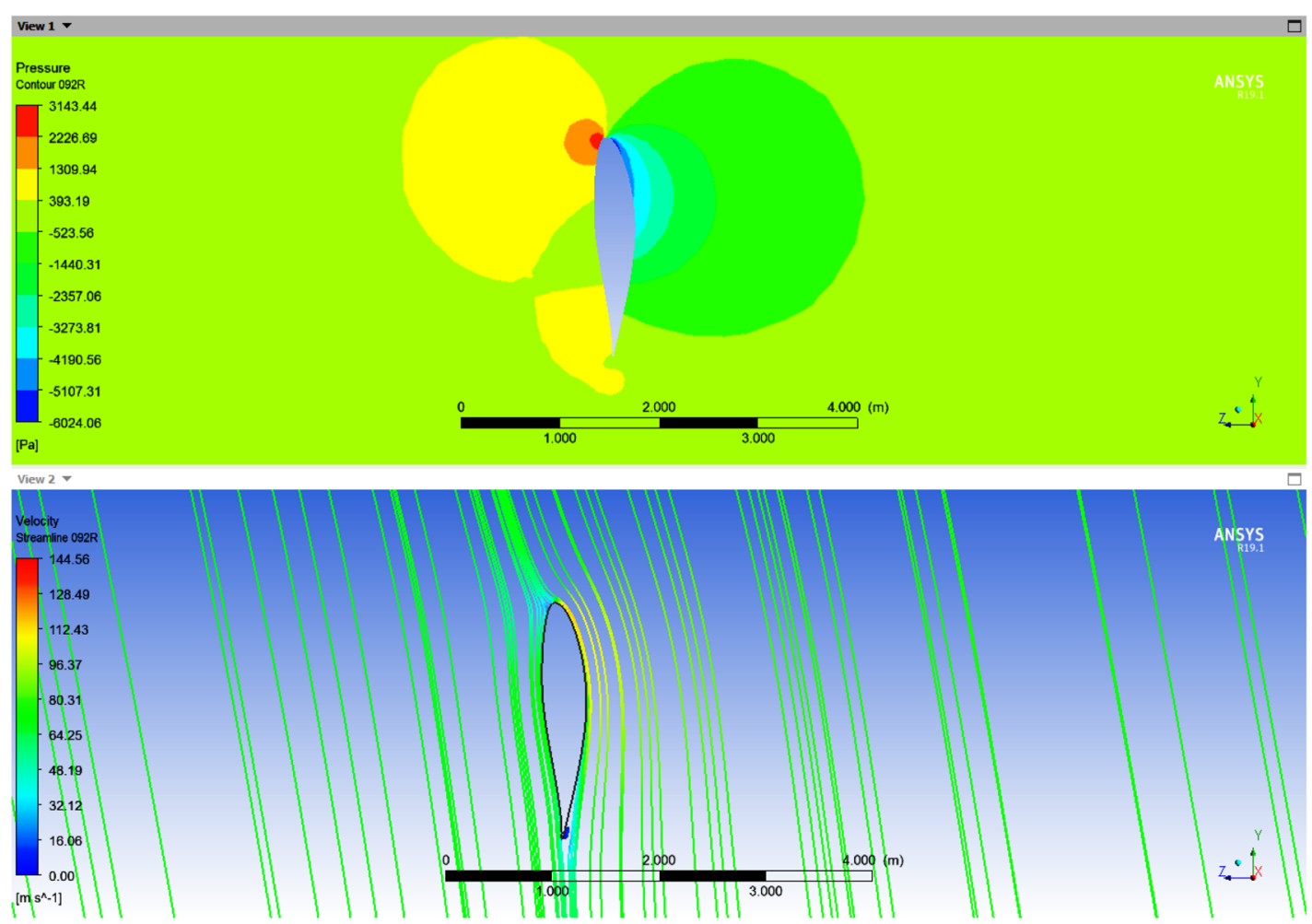

(a) $15 \mathrm{~m} / \mathrm{s}$

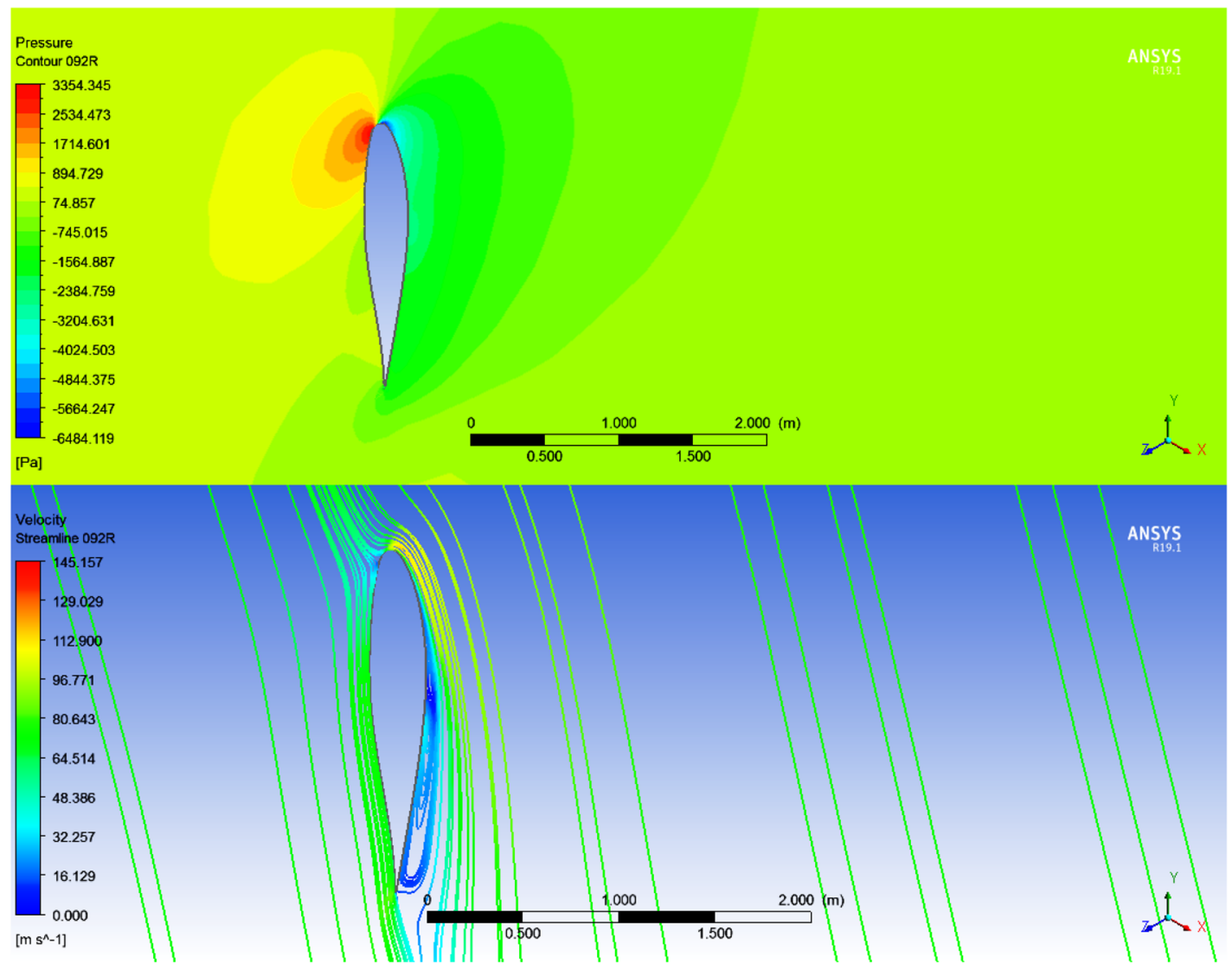

(b) $20 \mathrm{~m} / \mathrm{s}$

Fig. 15 Relationship between pressure contour and velocity streamlines in $92 \% \mathrm{R}$ 
adopted results up to $20 \mathrm{~m} / \mathrm{s}$ as compared to other turbulence models. Disperse prediction of flap-wise bending moment was also demonstrated at different wind speeds. Calculated pressure coefficients at three span-wise chords (32\% R, 60\% R and 92\% R) were compared for both 15 $\mathrm{m} / \mathrm{s}$ and $20 \mathrm{~m} / \mathrm{s}$ wind speeds. The influence of flow separation on prediction capability due to the effects of the adverse pressure was demonstrated near the root region. Although the $k-\omega$ SST model was found superior than other model in term of predictive capability, prediction of flow separation was found to be poor. $k-\epsilon$ Realizable and RNG versions were found to overestimate pressure coefficient, taking $k-\omega$ SST as a baseline model. The predictive ability of $k-\omega$ SST model could improve if the boundary layer is well arrested. The present study, therefore, recommends an alternative method of inflating the inflation layers around the blade surface such as employing first layer thickness instead of transition ratio.

Acknowledgements The authors acknowledges support from Mobility to Enhance Training of Engineering Graduates in Africa (METEGA) under the Intra ACP Mobility Schemes.

\section{Compliance with ethical standards}

Conflict of Interest The authors declare that they have no conflict of interest.

\section{References}

1. Fuglsang P, Madsen H A (1996) Numerical optimization of wind turbine rotors. In: Proceedings of European Union Wind Energy Conference, pp 679-682

2. Gomez-Iradi S, Barakos G (2008) Cfd investigation of wind turbine rotor design parameters. Proc Inst Mech Eng Part A J Power Energy 222(5):455-470

3. Cox K, Echtermeyer A (2012) Structural design and analysis of a $10 \mathrm{mw}$ wind turbine blade. Energy Proc 24:194-201

4. Tenguria N, Mittal N, Ahmed S (2010) Investigation of blade performance of horizontal axis wind turbine based on blade element momentum theory (BEMT) using naca airfoils. Int J Eng Sci Technol 2(12):25-35

5. de Freitas Pinto R LU, Gonçalves BPF (2017) A revised theoretical analysis of aerodynamic optimization of horizontal-axis wind turbines based on Bem theory. Renew Energy 105:625-636

6. Sun Z, Chen J, Shen WZ, Zhu WJ (2016) Improved blade element momentum theory for wind turbine aerodynamic computations. Renew Energy 96:824-831

7. Herráez I, Stoevesandt B, Peinke J (2014) Insight into rotational effects on a wind turbine blade using Navier-Stokes computations. Energies 7(10):6798-6822

8. Luo K, Zhang S, Gao Z, Wang J, Zhang L, Yuan R, Fan J, Cen K (2015) Large-eddy simulation and wind-tunnel measurement of aerodynamics and aeroacoustics of a horizontal-axis wind turbine. Renew Energy 77:351-362

9. Pérez-Segarra CD, Lehmkuhl O, Jaramillo J, Colomer G, Oliva A (2009) Turbulence modelling and numerical issues: from rans to dns and les. In: Actas da III Conferência Nacional em Mecânica de Fluidos, Termodinâmica e Energia (MEFTE-BRAGANÇA 09) p3 paper (in CD), pp 1-31

10. Abdelrahman $M$, Abdellatif $O$, Moawed $M$, Eliwa $A$, Mišák $S$ (2015) The cfd performance analysis for horizontal axis wind turbine with different blade shapes and tower effect. In: 2015 16th international scientific conference on electric power engineering (EPE), pp 754-759. IEEE

11. Malik A W, Uddin N, Haq S M H U, Khan M F U, Hayat S (2017) Modeling and simulation of a three-dimensional adjustable horizontal axis wind turbine blade, using a commercial computational fluid dynamics (cfd) code. In: ASME 2017 international mechanical engineering congress and exposition, pp. V007T09A077-V007T09A077. American Society of Mechanical Engineers

12. Fluent $A$ (2017) 18.0 ansys fluent theory guide 18.0. Ansys Inc

13. Spalart $P$, Allmaras $S$ (1992) A one-equation turbulence model for aerodynamic flows. In: 30th aerospace sciences meeting and exhibit, $\mathrm{p} 439$

14. Menter FR (1994) Two-equation Eddy-viscosity turbulence models for engineering applications. AIAA J 32(8):1598-1605

15. Yakhot V, Orszag S, Thangam S, Gatski T, Speziale C (1992) Development of turbulence models for shear flows by a double expansion technique. Phys Fluids A Fluid Dyn 4:1510-1520

16. Shih TH, Zhu J, Lumley JL (1993) A realizable reynolds stress algebraic equation model. NASA, Washington, D.C.

17. Villalpando F, Reggio M, llinca A (2011) Assessment of turbulence models for flow simulation around a wind turbine airfoil. Model Simul Eng 2011:6

18. Kekina P, Suvanjumrat C (2017) A comparative study on turbulence models for simulation of flow past naca 0015 airfoil using openfoam. In: MATEC web of conferences, vol 95, p 12005. EDP Sciences

19. Kody S, Alpman E, YIlmaz B (2014) Computational studies of horizontal axis wind turbines using advanced turbulence models. Marmara Univ J Sci 2(26):36-46. https://doi.org/10.7240/ MJS.2014266488

20. Jonkman J, Butterfield S, Musial W, Scott G (2009) Definition of a 5-mw reference wind turbine for offshore system development. In: Technical report, National Renewable Energy Lab.(NREL), Golden, CO (United States)

21. Siddiqui MS, Rasheed A, Kvamsdal T, Tabib M (2017) Quasi-static and dynamic numerical modeling of full scale nrel $5 \mathrm{mw}$ wind turbine. Energy Proc 137:460-467

22. Lanzafame R, Mauro S, Messina M (2013) Wind turbine cfd modeling using a correlation-based transitional model. Renew Energy 52:31-39

23. Jonkman J M, Buhl Jr M L, et al (2005) Fast user's guide. National Renewable Energy Laboratory, Golden, CO, Technical Report No. NREL/EL-500-38230

24. Ariff M, Salim SM, Cheah SC (2009) Wall y+ approach for dealing with turbulent flow over a surface mounted cube: part 1-low reynolds number. In: Seventh international conference on CFD in the minerals and process industries, pp 1-6

25. Wang L, Quant R, Kolios A (2016) Fluid structure interaction modelling of horizontal-axis wind turbine blades based on CFD and FEA. J.Wind Eng. Ind. Aerodyn. 158:11-25

26. Ansys: Lecture 6 turbulence modeling (2010). http://imechanica .org. Accessed June 022018

27. Tennekes H, Lumley JL (1972) A first course in turbulence. MIT press, Cambridge

28. Gebreslassie MG, Tabor GR, Belmont MR (2012) CFD Simulations for sensitivity analysis of different parameters to the wake characteristics of tidal turbine. Open J Fluid Dyn 2(3):56-64. https:// doi.org/10.4236/ojfd.2012.23006

29. Bazilevs Y, Hsu MC, Akkerman I, Wright S, Takizawa K, Henicke B, Spielman T, Tezduyar T (2011) 3d simulation of wind turbine 
rotors at full scale. Part i: Geometry modeling and aerodynamics. Int J Numer Methods Fluids 65(1-3):207-235

30. Zhao W, Cheng P, Wan D et al (2014) Numerical computation of aerodynamic performances of nrel offshore 5-mw baseline wind turbine. In: The Eleventh ISOPE Pacific/Asia offshore mechanics symposium. International society of offshore and polar engineers

31. Siddiqui MS, Rasheed A, Tabib M, Kvamsdal T (2016) Numerical analysis of nrel $5 \mathrm{mw}$ wind turbine: a study towards a better understanding of wake characteristic and torque generation mechanism. J Phys Conf Ser 753:032059

32. Sagol E, Reggio M, Ilinca A (2012) Assessment of two-equation turbulence models and validation of the performance characteristics of an experimental wind turbine by CFD. ISRN Mech Eng. https://doi.org/10.5402/2012/428671
33. Duque EP, Johnson W, VanDam C, Cortes R, Yee K (2000) Numerical predictions of wind turbine power and aerodynamic loads for the nrel phase ii combined experiment rotor. Technical report, National Aeronautics And Space Administration Moffett Field Ca Ames Research Center

34. Plaza B, Bardera R, Visiedo S (2015) Comparison of BEM and CFD results for mexico rotor aerodynamics. JWind Eng Ind Aerodyn 145:115-122

35. Muiruri PI, Motsamai OS (2018) Three dimensional cfd simulations of a wind turbine blade section; validation. J Eng Sci Technol Rev 11(1):138-145

36. Menter FR, Kuntz M, Langtry R (2003) Ten years of industrial experience with the sst turbulence model. Turbul Heat Mass Transfer 4:625-632 